\title{
SIMULATION BASED METHOD FOR DESIGN AND APPLICATION OF DIGITAL CONTROL SYSTEM
}

With increasing number of microprocessors and DSP use as a control system in power semiconductor converters, the new approaches for design of digital control system must be implemented. Designing a digital control system requires use of control to output transfer function. For new, frequency controlled resonant converters, like LLC converter, standard averaging methods cannot be applied for revealing the transfer function. Instead of that, new simulation based, numerical methods must be employed.

\section{Introduction}

In the field of DC/DC converters for switching power supplies, the main focus is on implementation of digital control, which means use of microcontrollers or DSP with implemented control algorithms and functions for communication with user as well. Analog control systems are well known and their design procedure is mastered, so it is easy to convert analog (continuous) controller into discrete and consequently implementing in microcontroller and DSP. But these methods ignore sample and hold effect of A/D converter and computing time of microprocessor. For proper discrete controller design, the method named direct digital design can be used. This method uses transfer function of converter in discrete form, including effect of sampling and computation delay [1].

For controller design purposes, transfer function of converter is necessary. This transfer function is based on model of power stage of controller. For PWM converters such as buck, boost, etc. the averaging method is widely used, but for new resonant topolo-

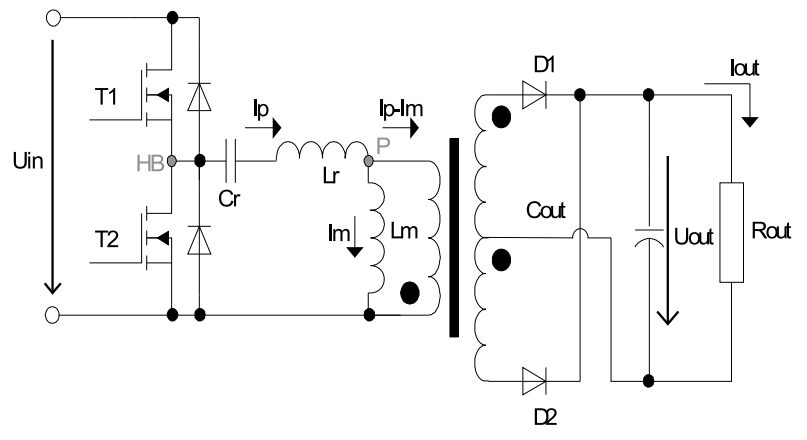

Fig. 1 Principal scheme of LLC converter gies such as LLC converter, with this averaging method, the control to output transfer function cannot be used.

Resonant converters are well-known due to their high efficiency and low EMI (Electromagnetic Interference) noise. Despite of that, their utilization in most of industry and consumer applications is still limited due to their disadvantages $[2,3,4,5]$.

The perspective topology for such application is LLC resonant converter (Fig. 1), which exists for very long time but because of lack of understanding of characteristic of this converter, it was used as a series resonant converter with passive load. The benefit of frequency controlled LLC resonant converter is narrow switching frequency range, with light load and ZVS (Zero Voltage Switching) capability with even no load also with wide input voltage range [6, 7].

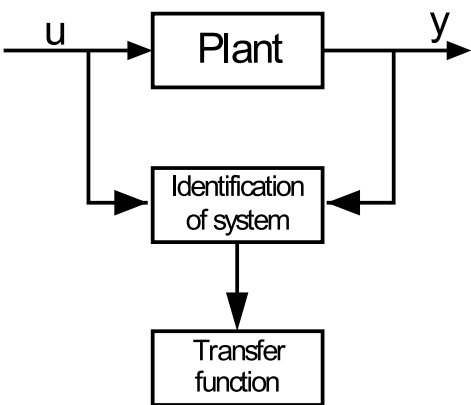

Fig. 2 Process of transfer function evaluation

In this paper, new simulation based method for obtaining the transfer function of converter is discussed. This method uses MATLAB and OrCad PSPICE environments for revealing the transfer

\footnotetext{
* Peter Drgona, Anna Prikopova, Michal Frivaldsky, Martin Priecinsky

Department of Mechatronics and Electronics, Faculty of Electrical Engineering, University of Zilina, Slovakia, E-mail: drgona@fel.uniza.sk
} 
function. Advantage of this method is that it can be used for every type of power converter. Next in the paper, the direct digital design of controller based on transfer function is discussed. This method uses MATLAB environment for designing the discrete controller.

\section{Transfer Function of Converter}

Design of digital control system for power converter requires control-to-output transfer function. Based on this transfer function, digital controller can be obtained. For PWM converters, standard "averaged" methods can be used for revealing the transfer function of converter. One method with good results is "direct circuit averaging". This method defines "local average operator", which means average value of parameter during unit of time.

$$
\bar{x}(t)=\frac{1}{T} \int_{t-T}^{t} x(t) d t
$$

The operator is defined at neglected ripple, which is caused by switching of semiconductor devices. After application of above mentioned operator, switching elements in power converter changes into blocks represented by functions of duty cycle and state variables. This method can be easily implemented for standard PWM converters such as boost, buck, flyback etc. Transfer function obtained with this method has a duty cycle as an input value and output voltage as an output value.

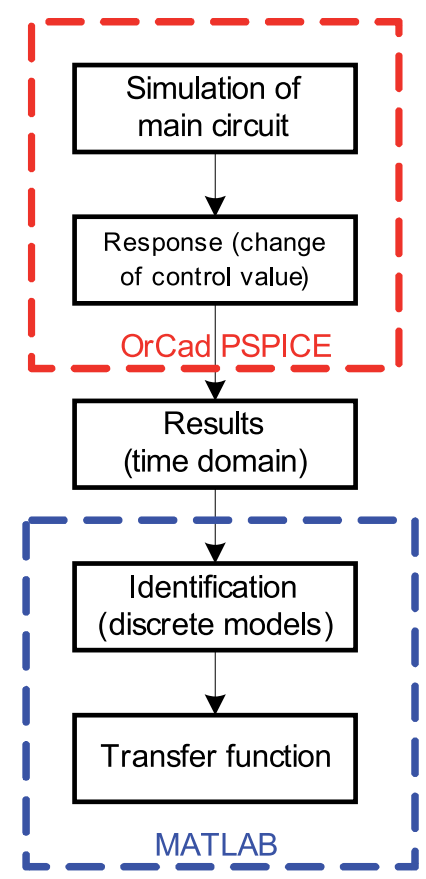

Fig. 3 Simulation based method for identification of transfer function

Unlike the PWM converters, the control transfer function of frequency controlled resonant converters cannot be obtained by the state space averaging method, due to different ways of energy processing. While the state space averaging methods eliminate the information about switching frequency, they cannot predict dynamic properties of resonant converters, so the proper control-to-output transfer function cannot be evaluated.

There are several methods for solving this problem, but some of them are too simplified and idealized, others are too complex and difficult to use [2,3]. In this paper, a new simulation based method for revealing the control transfer function is proposed.

This method is based on PSPICE simulation and use of System Identification Toolbox in MATLAB environment. First, the simulation of main circuit in PSPICE must be created. The simulation in PSPICE must be exact with all parasitic components taken into account. Using of PSPICE simulation, the dependency of output (voltage, current) on input (switching frequency, duty cycle) can be simulated. Data acquired from simulation in PSPICE are used in MATLAB System Identification Toolbox. Whole process used in this method is shown in Fig. 3.

Using this toolbox offers several models for identification of the system. With use of different models from System Identification Toolbox (SIT), identification of all converters is possible.

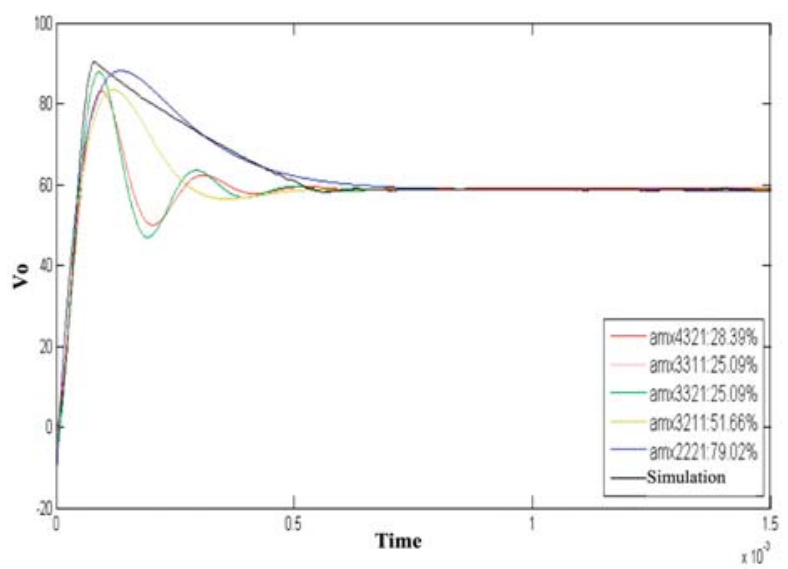

Fig. 4 Accuracy of ARMAX models with different degree (up to down 4, 3, 2)

System Identification Toolbox includes a number of models in continuous or discrete form, which can be used for identification of systems:

- ARX (Auto Regressive Exogenous Input Model)

- ARMAX (Auto Regressive Moving Average Exogenous Input Model)

- OE (Output Error Model)

- BJ (Box-Jenkins Model), SS (State-Space Model).

The simplest model is ARX, best accuracy offers models ARMAX, BJ and OE. Accuracy of the model depends also on degree of polynomials used in transfer function. Fig.4 shows accuracy of identified transfer function on its polynomial degree for ARMAX 
model of LLC converter. In most types of converters degree from 2 to 4 is sufficient. All models are in discrete form (z-domain), so the exact specification of sampling interval is necessary [8]. Sampling interval used for models in SIT must be equivalent with integration step used for simulation in OrCad PSPICE. Requested discrete transfer function is in form:

$$
G(z)=\frac{B(z)}{A(z)}=\frac{b_{0}+b_{1} z^{-1}+b_{2} z^{-2}+\ldots+b_{n b} z^{-n b}}{a_{0}+a_{1} z^{-1}+a_{2} z^{-2}+\ldots+a_{n a} z^{-n a}}
$$

The coefficients of the transfer function were acquired from ARMAX model of 2 nd degree. This model was chosen due to its best accuracy (79\%). After acquiring the transfer function, the proper discrete controller can be designed.

\section{Design of Discrete Controller}

Due to implementation in microprocessor, the controller must be in discrete form. There are two ways to design a discrete controller - design by emulation and direct digital design [5].

In the design by emulation approach, also known as digital redesign method (see Fig. 5), first an analog controller is designed in the continuous domain, by ignoring the effects of sampling and hold of A/D converter and computing delay of microprocessor. In next step, the controller can be converted into discrete-time domain by one of discretization method.

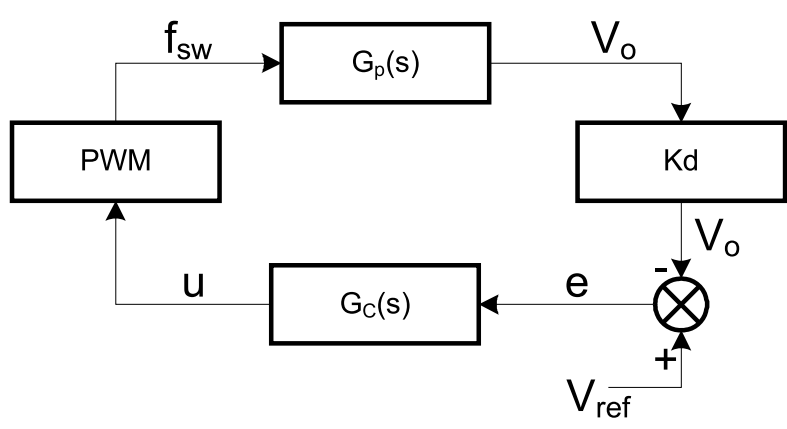

Fig. 5 Design of discrete controller by emulation

This approach is good for systems of lower degree, but in discrete systems of higher degree, the transient responses does not reflect the required values because of ignoring sample and hold and computation delay effects.

On the other hand, the direct digital design approach offers design of controller directly in z-domain, without conversion, including effects of $\mathrm{A} / \mathrm{D}$ converter and microprocessor. Block diagram of this approach is in Fig. 6.

Sampling of measured value with A/D converter can be represented by ideal Zero-Order-Hold block with sample time $T_{s}$. Gain of A/D converter is represented by block $K_{a d c}$. Computing delay of microprocessor, also with delay from PWM module are repre-

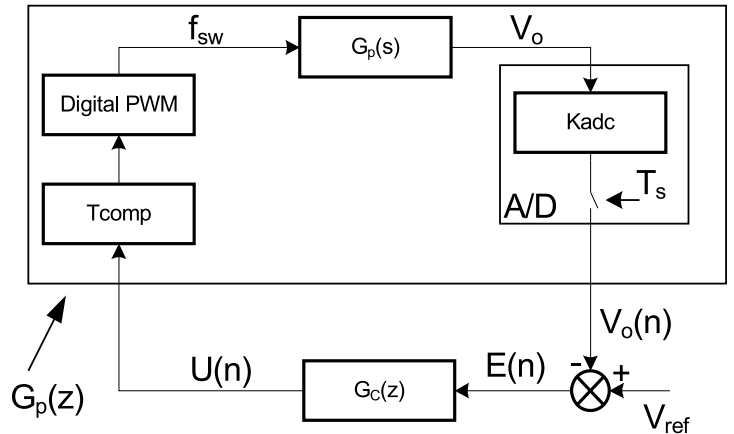

Fig. 6 Direct digital design control loop.

sented by block $T_{\text {comp }}$. A/D converter with PWM module together form a sampling-and-hold device. Sample and hold block brings additional time delay of $T_{s} / 2$ and phase lag of $\omega T_{s} / 2$, which means that reconstructed signal has time or phase lag $[1,9,10,11]$. The s-domain transfer function of sample and hold device is:

$$
S H(s)=\frac{1-e^{-s T_{s}}}{s}
$$

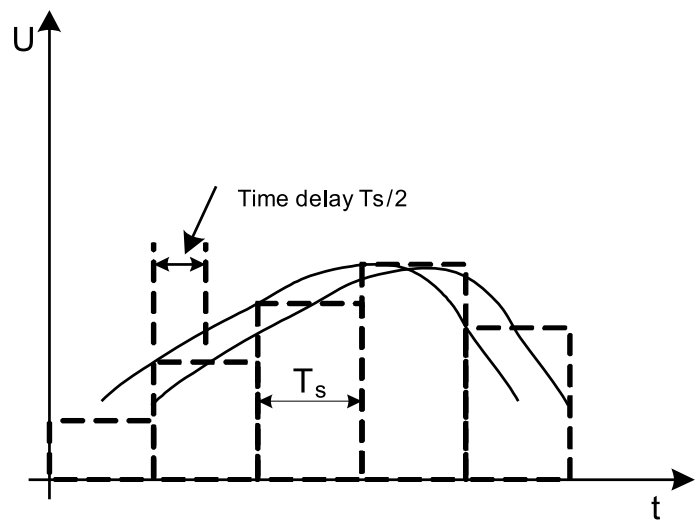

Fig. 7 Effect of "sample and hold" in discrete system

Block $T_{\text {comp }}$ represents delay between conversion of A/D converter and PWM duty cycle or modulo update. Time between these two events is necessary for computing the values for PWM block. Transfer function of block Tcomp is:

$$
H_{C}(s)=e^{-s T_{d}}
$$

Discrete transfer function of the whole converter including Zero-Order block, Sample-and-Hold effect and gain of A/D converter is:

$$
G(z)=Z\left\{\frac{1}{s}\left(1-e^{s T_{s}}\right) \cdot H_{C}(s) \cdot G_{P}(s) \cdot K_{d}\right\}
$$


Fig. 8 shows effect of sampling interval with computing delay on stability of closed control loop. Table 1 shows different transfer functions with different sampling intervals and different computational delays. Transfer functions without computing delay, are marked Gz1 and Gz2. In transfer functions marked Gdlyz1 to Gdlyz4, the effects of computing delays from 3 to $6 \mu$ are implemented. Sampling times were used from A/D converter included in DSC 56F8013 also the computing times were used from same processor. Application was for digital control system for $200 \mathrm{kHz}$ multiresonant converter. In this system discrete regulator of third order was used [4].

Sampling times and computational delays

Tab. 1 for transfer functions in Fig. 6

\begin{tabular}{|c|c|c|}
\hline Sampling time $T_{s}$ & Computing delay $T_{\text {comp }}$ & Mark \\
\hline $5 \mu \mathrm{s}$ & 0 & Gz1 \\
\hline $10 \mu \mathrm{s}$ & 0 & Gz2 \\
\hline $5 \mu \mathrm{s}$ & $3 \mu \mathrm{s}$ & Gdlyz1 \\
\hline $10 \mu \mathrm{s}$ & $3 \mu \mathrm{s}$ & Gdlyz2 \\
\hline $5 \mu \mathrm{s}$ & $6 \mu \mathrm{s}$ & Gdlyz3 \\
\hline $10 \mu \mathrm{s}$ & $6 \mu \mathrm{s}$ & Gdlyz4 \\
\hline
\end{tabular}

From Fig. 8 is clear that computing delay has significant effect on stability of closed control loop. With rising computing and sampling time stability of control system drops.

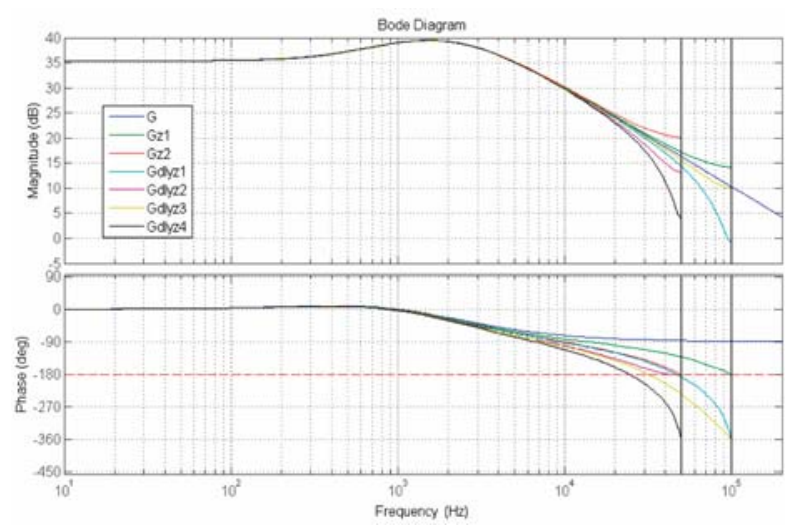

Fig. 8 Effect of sample and hold and computation delay on stability of control loop

For design of controller in z-domain, all above mentioned delays must be taken into account. With use of MATLAB Siso Design Tool, the proper discrete controller can be designed. This tool offers a wide palette of tools, including Graphic User Interface for direct controller design in discrete or continuous domain. Advantage of this tool is possibility of direct placing of zeroes and poles of controller on point diagram of closed or open loop. After placing the poles or zeros of controller, the different responses of closed control loop can be displayed for verification.

\section{Implementation in DSC}

Discrete controller proposed in previous chapter was implemented into 16b digital signal controller (DSC) Freescale 56F8013, which is primary designed for motor and converter control. Advantage of this microprocessor are high performance peripherals which can operate with $96 \mathrm{Mhz}$ clock frequency. On the other hand, disadvantage of this processor is low core frequency $-32 \mathrm{MHz}$, and fixed point arithmetic. For better performance, fraction arithmetic with intrinsic functions were used in this DSC [12, 13].

Block scheme of digital control system with DSC 56F8013 on $200 \mathrm{kHz}$ LLC converter is in Fig. 9. For better performance and lower amount of additional hardware, the concept with microprocessor on secondary side of converter was used. Also, new available fast digital isolators were used instead of standard optocouplers.

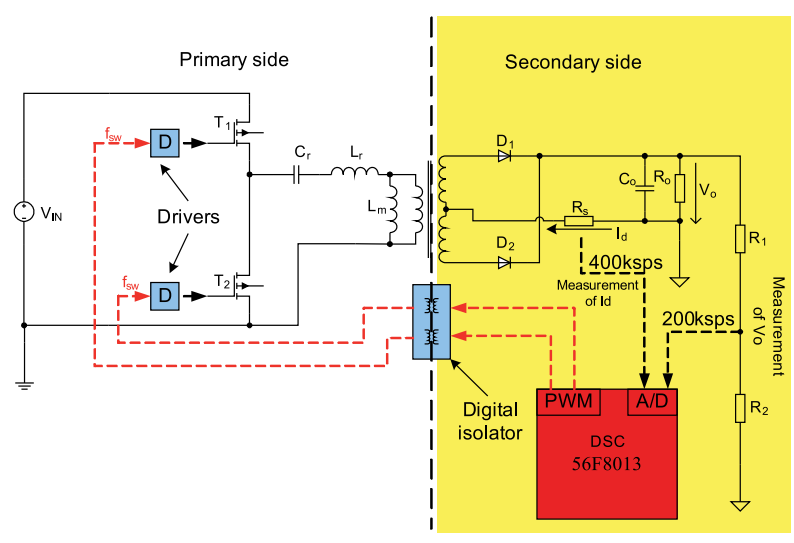

Fig. 9 Block scheme of full digital control system with DSC 56 F8013

Another option for implementation is use of $32 \mathrm{~b}$ microprocessor ColdFire V1 which offers better computing performance, but sampling time of $\mathrm{A} / \mathrm{D}$ converter is twice as in DSC 56F8013. For measurement of output voltage, this time is sufficient, but for current sensing, the A/D converter on ColdFire is too slow. This problem was eliminated by use of special algorithm for computing of diode current from value of output voltage, value of load and ripple of output voltage. This algorithm is based on computing of output current from output voltage drop, during load connection. Detailed method is described in [3]. Times required for computing on both processors are in Table 2 .

\section{Verification ofProposed Full Digital System}

Measurements of the full digital control system were realized on $60 \mathrm{~V} / 25 \mathrm{~A}$ LLC converter with use of $16 \mathrm{~b} 56 \mathrm{~F} 8013 \mathrm{DSC}$. The block scheme for measurement circuit is shown in Fig. 9. For correct 
Sampling times and computational delays for two processors

\begin{tabular}{|c|c|c|c|c|c|}
\hline Processor & Bits & $\begin{array}{c}\text { Core } \\
\text { frequency }\end{array}$ & $\begin{array}{c}\text { A/D } \\
\text { sampling } \\
\text { time }\end{array}$ & $\begin{array}{c}\text { Computing } \\
\text { of control } \\
\text { loop }\end{array}$ & $\begin{array}{c}\text { Computing } \\
\text { of current } \\
\text { value }\end{array}$ \\
\hline $56 \mathrm{~F} 8013$ & $16 \mathrm{~b}$ & $32 \mathrm{Mhz}$ & $1.126 \mu \mathrm{s}$ & $2.98 \mu \mathrm{s}$ & $3.01 \mu \mathrm{s}$ \\
\hline ColdFireV1 & $32 \mathrm{~b}$ & $50.3 \mathrm{Mhz}$ & $2.252 \mu \mathrm{s}$ & $1.8 \mu \mathrm{s}$ & $1.12 \mu \mathrm{s}$ \\
\hline
\end{tabular}

start of the converter, the soft-start algorithm, when switching frequency is twice as normal $(400 \mathrm{kHz})$, was used. Fig. 10 shows point when soft-start ends and algorithm takes control.

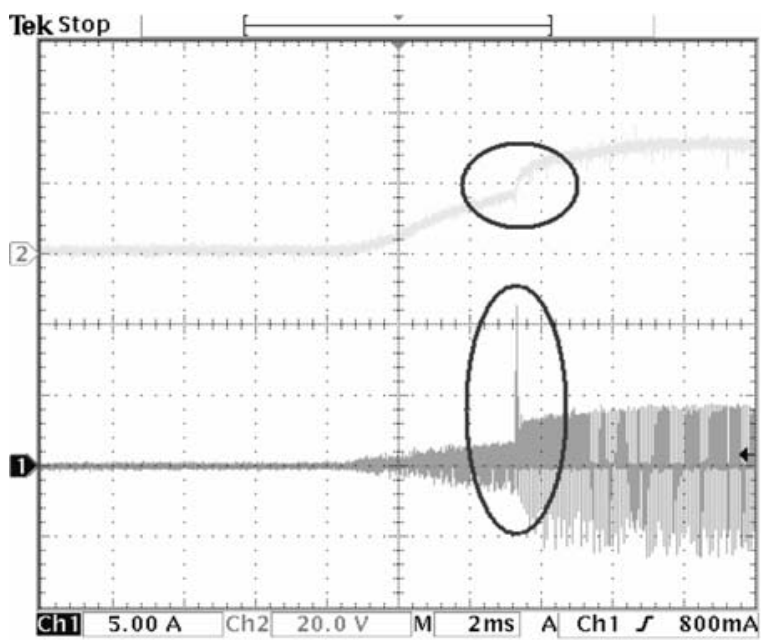

Fig. 10 Measured waveforms during soft start: (top to down): output voltage (2), load current(1)

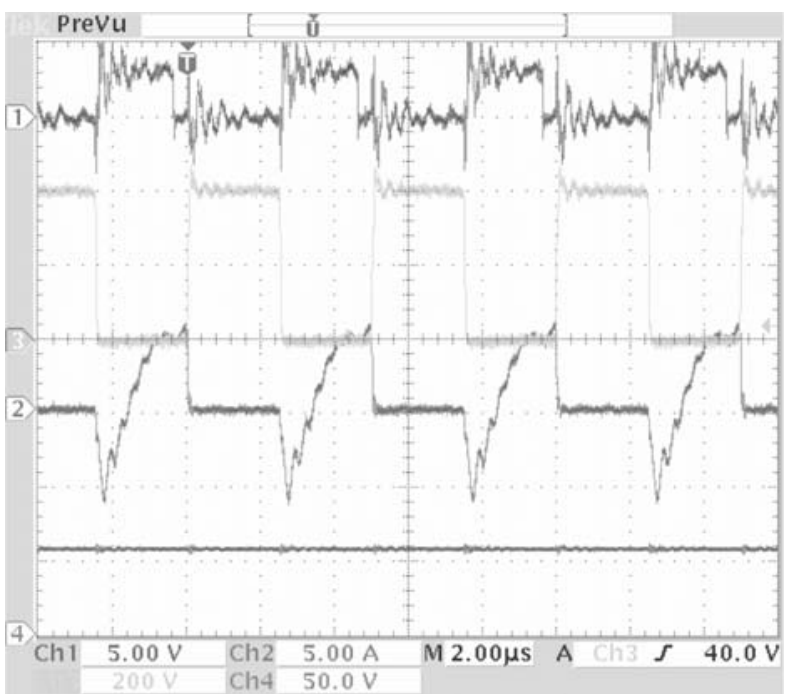

Fig. 11 Measured waveforms with digital control system - no load: (top to down): pwm pulses(1), transistor voltage(3), transistor current(2), output voltage(4)
Waveforms from digital control system at no load condition are shown in Fig. 11 - output voltage 58.8V at $201 \mathrm{kHz}$ switching frequency.

For measurements of control systems at full load conditions, the requested output voltage was changed to $50 \mathrm{~V}$ due to lower tolerance of used MOSFETs against current peaks. Input voltage was $325 \mathrm{~V}$ due to verification of dynamic properties of controllers. Fig. 12 shows waveforms from digital control system with microprocessor. Output voltage was $48 \mathrm{~V}$ at $160 \mathrm{kHz}$ switching frequency.

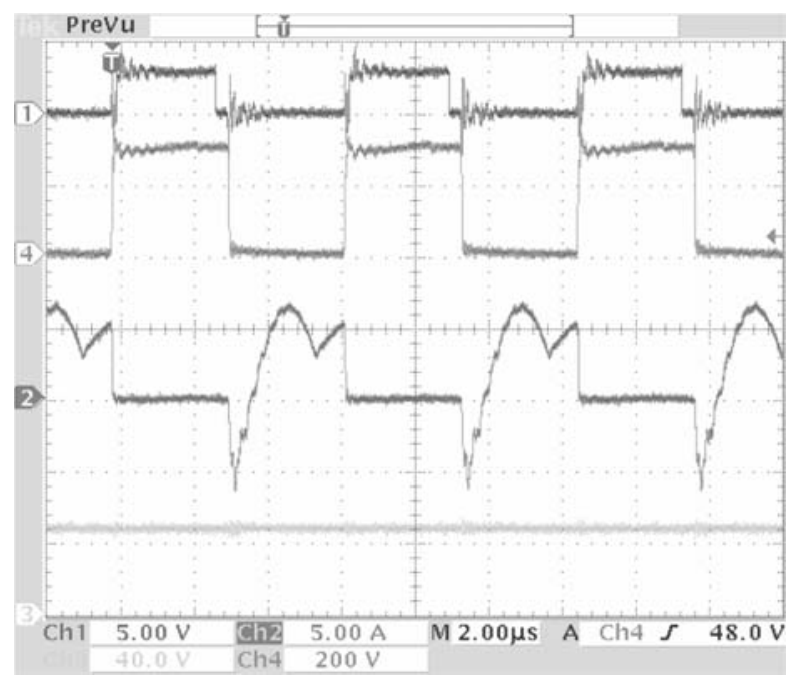

Fig. 12 Measured waveforms with digital control system - full load: (top to down): pwm pulses(1), transistor voltage(4), transistor current(2), output voltage(3)

\section{Conclusion}

In this paper the new approach for design of digital control system with discrete controller is described. Proposed method for revealing the control to output transfer function is based on numerical simulations from widely used OrCad PSPICE environment. Major advantage of this method is possibility of use for every power semiconductor converter, non-isolated, isolated, PWM, PSM or frequency controlled. Also, the exact analysis of operating intervals is not necessary, because this method requires only two values control (input) and output.

Consequently, for discrete controller design, two methods were proposed. While both methods of digital controller design "design by emulation and direct digital design - have their benefits to the developer, the first method, namely design by emulation, allows the power supply designers to do the control design in the familiar s-domain and then convert it to a discrete/digital controller. Disadvantage of this method is inaccurate representation in digital control system.

The second approach known as direct digital design, allows digital controller design directly in z-domain and results in better 
dynamic performance for the closed loop operation of the converter - especially with use in microcontroller or DSP. All of these MATLAB based designed controllers were finally validated by experimental results. Comparison of measured waveforms at full load shows good accuracy for digital control system. On the other hand, from measurements at no load condition results that digital control system has lower resistance against EMI $[14,15]$. Also, the stability of digital control system was low, due to longer computing time compared to switching frequency of converter $(200 \mathrm{k} \mathrm{Hz})$. This problem can by solved by the use of faster microprocessor as described in the paper, or by eliminating of current control loop with special algorithm for computing of output current - this option is described in [4].
All experimental results are described more in detail in $[2,3$, 4].

\section{Acknowledgment}

The authors wish to thank for the project VEGA "Research of Topology and Control of Power Electronic Supply System with Single-Phase HF Input and Two-Phase Orthogonal Output for TwoPhase SM/IM Electrical Motors”. Next to grant agency APVV project No. 20-051705 and no. APVV-0535-07. Also we would like to thank for VMSP-P-0085-09 and LPP-0366-09

\section{References}

[1] CHOUDBURY, S.: Designing a DSP-based Digitally Controlled DC-DC Switching Power Supply, Texas Instruments, 2006

[2] YANG, B.: Topology Investigation of Front end DC/DC Converter for Distributed Power System. Dissertation Thesis, Virginia Tech, 2003

[3] FRIVALDSKY, M.: Experimental Analysis of Commutation Modes of Various Power Transistor Structures and its Verification and Implementation in Selected Converter's Topology. Dissertation Thesis, University of Zilina, 2009

[4] DRGONA, P.: Optimisation of Control System of Power LLC Converter. Dissertation Thesis, University of Zilina, 2009

[5] FAIRCHILD SEMICONDUCTOR: Half-bridge LLC Resonant Converter Design Using FSFR Series Fairchild Power Switch, Application Note, AN-4151, 2007

[6] HANGSEOK, CH.: Analysis and Design of LLC Resonant Converter with Integrated Transformer, 1-4244-0714-1/07, 2007 IEEE

[7] JEE-HOON, J., JOONG-GI, K.: Theoretical Analysis and Optimal Design of LLC Resonant Converter, SAMSUNG Electronics CO., Lts./Digital Printing Division

[8] MOUDGALYA, K.N.: Digital Control, John Wiley and Sons, p.157-237, 2007

[9] LIJUNG, H., ZHENGYU, L., ZHAOMING, O.: Research of Digital Control Strategy for Multi-resonant LLC Converter, 1-42440755-9/07, 2007 IEEE

[10] BALATE, J.: Automatic Control (in Czech), BEN - technicka literatura, Praha, 2004

[11] PEPA, E.: Adaptive Control of a Step-Up Full-Bridge DC-DC Converter for Variable Low Input Voltage Applications, Virginia Polytechnic Institute, 2004

[12] FILKA R., BALAZOVIC P., DOBRUCKY, B.: A Sensorless PM Synchronous Motor Drive for Electric Washers, Communications - Scientific Letters of the University of Zilina, 2007

[13] ASHRAFZADEH, A.: Power Management: Analog control vs. Digital, EE Times Online, Embedded.com, 2007

[14] HRIANKA, M., LAKATOS, J., HARGAS, L., KONIAR, D.: Modeling Simulation and Verification of Heat Transfer in Power Transistor Cooler, Metalurgija (Metallurgy), Vol. 49, No. 2, 2010, ISSN 1334-2576

[15] DOBRUCKY, B., SPANIK, P., SUL, R.: Improvement of Power Electronic Structure Characteristics Using SiC Technologyoverview, Communications - Scientific Letters of the University of Zilina, 2006. 